\title{
Effects of microRNA-26b on proliferation and invasion of glioma cells and related mechanisms
}

\author{
YUN-PING LI, WEI-MIN DAI, QIANG HUANG, YUAN-QING JIE, GUO-FENG YU, \\ XIAO-FENG FAN, AN WU and DAN-DAN MAO \\ Department of Neurosurgery, Quzhou People's Hospital, Quzhou Hospital of Zhejiang University, \\ Quzhou, Zhejiang 324000, P.R. China
}

Received September 13, 2016; Accepted May 22, 2017

DOI: $10.3892 / \mathrm{mmr} .2017 .7121$

\begin{abstract}
Neuroglioma is the most common primary malignant tumor in neurosurgery. Due to its short survival period and high patient mortality rate, neuroglioma is a major challenge in clinics. Elucidating the pathogenic mechanisms and associated molecular targets of neuroglioma can therefore benefit diagnosis and treatment of glioma. Previous studies have established the role of microRNA (miR)-26b in various tumors, including breast cancer, lymphoma and glioma. Its function and mechanism in neuroglioma, however, remains to be elucidated. In the present study, in vitro cultured U87 glioma cells were randomly divided into miR-26b mimic, miR-26b inhibitor and respective control (NC) groups. MTT assay was performed to detect the effect of miR-26b on cell proliferation, while a cell invasion assay detected its effects on cell invasion. Caspase-3 activity was also quantified to test cell apoptosis, followed by reverse transcription-quantitative polymerase chain reaction and western blotting to detect the variation of Bcl-2 expression under the effect of miR-26b. miR-26b mimics transfection upregulated its expression in U87 cells, which had significantly reduced Bcl-2 mRNA and protein expression levels and higher casapse 3 activity, and inhibited cell proliferation and invasion compared with the control group. The transfection of miR-26b inhibitor, in contrast, facilitated U87 cell proliferation and invasion, inhibited caspase- 3 activity and elevated Bcl-2 mRNA/protein expression. In conclusion, miR-26 could facilitate apoptosis and inhibit proliferation/invasion of neuroglioma cells via downregulating Bcl-2 expression and potentiating caspase-3 activity.
\end{abstract}

Correspondence to: Dr Wei-Min Dai, Department of Neurosurgery, Quzhou People's Hospital, Quzhou Hospital of Zhejiang University, 2 Zhongloudi Road, Quzhou, Zhejiang 324000, P.R. China

E-mail: weimindaid@sina.com

Key words: neuroglioma, microRNA-26b, B-cell lymphoma 2, caspase-3, cell proliferation, cell invasion

\section{Introduction}

As the most common malignant tumor in neurosurgery, neuroglioma has high invasiveness and unfavorable prognosis among all primary intracranial tumors of central nervous system (CNS) $(1,2)$. Predominantly originated from neural epithelial ectoderm, neuroglioma frequently occurrs in the cerebral hemisphere. Major pathological sub-types include medulloblastoma, oligodendroglioma, ependymoma and astrocytoma, with multifocal glioma as the most frequent type $(3,4)$. Neuroglioma has a high incidence among all intracranial tumors, and has gradually increased over the years (5). In China, neuroglioma is also the primary malignant tumor of CNS, with the age of onset becoming younger (6). Current treatment plans for neuroglioma include surgery, and radio- or chemo-therapy. However, due to its complicated pathogenesis, surgical options are limited $(7,8)$. Residual tumor of glioma may further proliferate, accompanied with invasive growth, leading to unsatisfactory treatment efficacy, thus severely affecting patient survival quality, and causing shortened survival time and higher mortality, all of which forms a major challenge for tumor treatment $(9,10)$. Therefore, elucidation of the pathogenic mechanisms and potential molecular targets of neuroglioma may benefit the diagnosis and treatment.

MicroRNAs (miRs) are small molecule RNAs with 19-25 nucleic acids, with common biological properties involved in body functions. Having multiple functions, miRs regulate body growth and potentiate the body's acclimation to the environment. Due to its variable existing forms, miRs may be regulated by physiological and developmental signals $(11,12)$. Each miR could regulate $>200$ target genes, suggesting that at least one third of human functional protein coding genes are regulated by miRs (13). A previous study demonstrated the role of miR as oncogene or tumor suppressor genes in tumor pathogenesis and progression (14). Another study revealedabnormal expression of miR-26b in breast cancer or lymphoma $(15,16)$. Its role and mechanism in glioma, however, remains to be fully illustrated. Therefore, the present study investigated the function and mechanism of miR-26b on proliferation and invasion of glioma cells.

\section{Materials and methods}

Equipment and reagents. The U87 human glioma cell line was purchased from the American Type Culture Collection 
(Manassas, VA, USA). Dulbecco's modified Eagle's medium (DMEM) fetal bovine serum (FBS) and streptomycin-penicillin were purchased from Hyclone; GE Healthcare (Chicago, IL, USA). Dimethyl sulfoxide (DMSO) and MTT were purchased from Gibco; Thermo Fisher Scientific, Inc. (Waltham, MA, USA). Trypsin-EDTA digestion buffer was purchased from Sigma-Aldrich; Merck KGaA (Darmstadt, Germany). A caspase-3 activity assay kit and polyvinylidene difluoride (PVDF) membranes were purchased from Pall Life Sciences (Port Washington, NY, USA). EDTA was purchased from Hyclone; GE Healthcare. Chemical reagents for western blotting were purchased from Beyotime Institute of Biotechnology (Haimen, China). An enhanced chemiluminescence (ECL) reagent was purchased from Amersham; GE Healthcare. Rabbit anti-human B-cell lymphoma 2 (Bcl-2) monoclonal antibody (cat. no. 4223), goat anti-rabbit horseradish peroxidase (HRP)-conjugated IgG secondary antibody (cat. no. 7074) and rabbit $\beta$-actin antibody (cat. no. 4970) were purchased from Cell Signaling Technology, Inc. (Danvers, MA, USA). A Transwell chamber was purchased from Corning Incorporated (Corning, NY, USA). A RNA extraction kit and reverse transcription kit were purchased from Axygen, Inc. (Union City, CA, USA). Other reagents were purchased from Sangon Biotech Co., Ltd. (Shanghai, China).

Glioma U87 cell culture and grouping. Liquid-nitrogen stored U87 cell line was incubated at $37^{\circ} \mathrm{C}$ until completely thawed. Cells were centrifuged at $450 \mathrm{x}$ g for $3 \mathrm{~min}$ at $37^{\circ} \mathrm{C}$, and were re-suspended in $1 \mathrm{ml}$ fresh culture medium. Cells were transferred to a 5-ml culture flask containing $3 \mathrm{ml}$ fresh culture medium. Cells were kept in a humidified chamber with $5 \% \mathrm{CO}_{2}$ at $37^{\circ} \mathrm{C}$ for $24-48 \mathrm{~h}$. U87 cells were seeded into 6 -well plates at $1 \times 10^{5}$ cells $/ \mathrm{cm}^{2}$. Culture medium contained $10 \%$ FBS and 90\% high-glucose DMEM medium (with $100 \mathrm{U} / \mathrm{ml}$ penicillin and $100 \mu \mathrm{g} / \mathrm{ml}$ streptomycin). Cells were cultured in a humidified chamber in $5 \% \mathrm{CO}_{2}$ at $37^{\circ} \mathrm{C}$, with the medium changed every other day and passaged every $2 \sim 3$ days. U87 cells at the log growth phase (2nd to 8th generation) were randomly divided into four groups: miR-26b mimics negative control (NC), miR-26b inhibitor NC, miR-26b mimics and miR-26b inhibitor group.

Liposome transfection of miR-26b mimics and miR-26b inhibitor. miR-26b mimics (5'-ACA AUGUUCAUCGGU GUGGA-3') and miR-26b inhibitor (5'-AUGACCGGUUUG GUCAGA-3') were transfected into U87 cells, in parallel with their respective NC oligonucleotides (miR-26b mimics NC, 5'-AUGCAUCCGGUAGGCAUGAUG-3'; miR-26b inhibitor NC, 5'-ACAAGGGUUCGCGUAUAGGUG-3'). Cells were cultured in 6-well plates until 70-80\% confluence. All plasmids were mixed in $200 \mu \mathrm{l}$ serum-free medium for a 15 -min incubation at room temperature. Lipofectamine 2000 mixture (Invitrogen; Thermo Fisher Scientific, Inc.) was then added with plasmid dilutions, followed by a 30 -min incubation at room temperature. The serum was then removed, followed by washing with PBS. Serum-free medium $(1.6 \mathrm{ml})$ serum-free medium was then added into the system. The mixture was then incubated in a humidified chamber with $5 \% \mathrm{CO}_{2}$ at $37^{\circ} \mathrm{C}$. After $6 \mathrm{~h}$, serum-containing medium was applied for a 48-h continuous incubation.
Reverse transcription-quantitative polymerase chain reaction (RT-qPCR) for miR-26b and Bcl-2 expression. TRIzol reagent (Invitrogen; Thermo Fisher Scientific, Inc.) was used to extract RNA from U87 tumor cells. According to the manufacturer's protocol, reverse transcription was performed to synthesize cDNA. Primers were designed by Primer 6.0 software based on target gene sequence, and were synthesized by Yingjun Biotechnology Co., Ltd. (Guangzhou, China) as presented in Table I. qPCR was performed on all target genes under the following conditions: $56^{\circ} \mathrm{C}$ for $1 \mathrm{~min}$, followed by 35 cycles each containing $92^{\circ} \mathrm{C}$ for $30 \mathrm{sec}, 58^{\circ} \mathrm{C}$ for $45 \mathrm{sec}$ and $72^{\circ} \mathrm{C}$ for $35 \mathrm{sec}$. Data were collected and calculated for $\mathrm{Cq}$ values of all standards and samples based on fluorescence quantification and the GAPDH housekeeping gene. A standard curve was plotted and relative gene expression was quantified according to the comparative Cq method (17).

MTT assay for cell proliferation. U87 cells at the log phase were seeded into 96-well plates containing DMEM medium supplemented with $10 \%$ FBS at a density of $5 \times 10^{3}$ cells/well. After a 24-h incubation, the supernatant was removed. Cells were then randomly divided into four groups: miR-26b mimics $\mathrm{NC}$, miR-26b inhibitor NC, miR-26b mimics and miR-26b inhibitor, all of which were treated as aforementioned. After $48 \mathrm{~h}, 20 \mu 1$ sterile MTT was added into each well in triplicate for each group. After a 4-h incubation, the supernatant was removed, $150 \mu 1$ DMSO was added and the mixture was vortexed for $10 \mathrm{~min}$ until violet crystals had completely resolved. Absorbance (A) values at $570 \mathrm{~nm}$ were measured to calculate proliferation rate of all groups using a microplate reader. Each experiment was repeated at least three times.

Transwell chamber assay for cell invasion. Following the manufacturer's protocol, serum-free medium was firstly applied. After $24 \mathrm{~h}$, a Transwell chamber was pre-coated using $50 \mathrm{mg} / \mathrm{l}$ Matrigel dilutions with its bottom and upper phase, followed by air drying at $4^{\circ} \mathrm{C}$. DMEM supplemented with 10\% FBS $(500 \mu \mathrm{l})$ and $100 \mu \mathrm{l}$ tumor cell suspension in serum-free medium were added into the inner and outer space of the chamber, respectively. The chamber was placed in a 24-well plate. In the control group, a Transwell chamber without Matrigel coating was applied. After a 48-h incubation, PBS was used to rinse the Transwell chambers, whose cells on the membrane were removed and fixed in cold ethanol. With crystal violet staining, cells in the lower layer of the membrane were counted under a light microscope. Each experiment was repeated three times.

Caspase-3 activity assay. Caspase-3 activity in all cells was measured using a test kit following the manufacturer's protocol. In brief, cells were digested by trypsin and centrifuged at $600 \mathrm{x} \mathrm{g}$ at $4^{\circ} \mathrm{C}$ for $5 \mathrm{~min}$. The supernatant was removed, with the addition of cell lysis buffer for $15 \mathrm{~min}$ on ice. The mixture was then centrifuged at $20,000 \times \mathrm{g}$ for $5 \mathrm{~min}$ at $4^{\circ} \mathrm{C}$. Ac-DECD-pNA ( $2 \mathrm{mM})$ was added to observe optical density value changes at $405 \mathrm{~nm}$ using a microplate reader. Caspase- 3 activity was then deduced.

Western blotting for Bcl-2 protein expression. U87 cell proteins were extracted using radioimmunoprecipitation assay 
Table I. Primer sequences for reverse transcription-quantitative polymerase chain reaction.

Target gene

Forward (5'-3')

Reverse $\left(5^{\prime}-3^{\prime}\right)$

$\begin{array}{ll}\text { GAPDH } & \text { AGTACCAGTCTGTTGCTGG } \\ \text { miR-26b } & \text { CTTAGTGGTCTCTACTTGTT } \\ \text { Bcl-2 } & \text { CCCACCTCTTCTAGAATCT }\end{array}$

Bcl-2, B cell lymphoma 2; miR, microRNA.

lysis buffer $(150 \mathrm{nM} \mathrm{NaCl}, 1 \% \mathrm{NP}-40,0.1 \% \mathrm{SDS}, 2 \mu \mathrm{g} / \mathrm{ml}$ aprotinin, $2 \mu \mathrm{g} / \mathrm{ml}$ leupeptin, $1 \mathrm{mM}$ PMSF, $1.5 \mathrm{mM}$ EDTA and $1 \mathrm{mM}$ NaVanadate) containing proteinase inhibitor and were incubated on ice for 15-30 min. Cells were ruptured for $5 \mathrm{sec}$ (4 times) and were centrifuged at $4^{\circ} \mathrm{C}$ at $10,000 \mathrm{x}$ g for $15 \mathrm{~min}$. The supernatant was transferred to a new tube and stored at $-20^{\circ} \mathrm{C}$ after protein quantification using a bicinchoninic acid protein assay kit (Thermo Fisher Scientific, Inc.). Equal amounts of extracted protein samples $(30 \mu \mathrm{g})$ were separated by $1 \%$ SDS-PAGE, and were transferred to a PVDF membrane. Non-specific binding was blocked using 5\% non-fat milk powder for $2 \mathrm{~h}$. Membranes were then incubated with anti-Bcl-2 and anti- $\beta$-actin primary antibodies (dilution, $1: 1,000$ ) at $4{ }^{\circ} \mathrm{C}$ overnight. The next day, PBS containing Tween-20 (PBST) was used to wash the membrane, followed by incubation at $37^{\circ} \mathrm{C}$ in the dark for $30 \mathrm{~min}$ with a HRP-conjugated secondary antibodies (dilution, 1:2,000). The membrane was then rinsed with PBST and incubated with ECL reagents for $1 \mathrm{~min}$. After $\mathrm{X}$-ray exposure, a protein imaging system and Quantity One software version 4.6 (Bio-Rad Laboratories, Inc., Hercules, CA, USA) were used to scan X-ray films and measure band density. Each experiment was repeated 4 times.

Statistical analysis. All data were presented as the mean \pm standard deviation. The statistical significance of the differences between groups was assessed using Student's t-test for pair-wise comparisons or one-way analysis of variance followed by a post hoc Bonferroni test for multiple comparisons. SPSS software version 11.5 (SPSS, Inc., Chicago, IL, USA) was used for statistical analysis. $\mathrm{P}<0.05$ was considered to indicate a statistically significant difference.

\section{Results}

miR-26b expression in U87 cells. RT-qPCR was used to detect the expression of miR-26b in U87 cells transfected with miR-26b mimics or inhibitors. As presented in Fig. 1, transfection of miR-26b mimics significantly upregulated the expression of miR-26b in U87 cells ( $\mathrm{P}<0.05$ vs. mimics NC group). The transfection of miR-26b inhibitor, however, effectively inhibited miR-26b expression in U87 cells $(\mathrm{P}<0.05$ vs. inhibitor NC group).

$U 87$ cell proliferation by $\mathrm{miR}-26 \mathrm{~b}$ regulation. MTT assay was used to detect the effect of miR-26b mimics or inhibitor on U87 cell proliferation. The results demonstrated significant inhibition of U87 cell proliferation by upregulating miR-26b via transfecting mimics ( $\mathrm{P}<0.05$ vs. mimics $\mathrm{NC}$ group). In

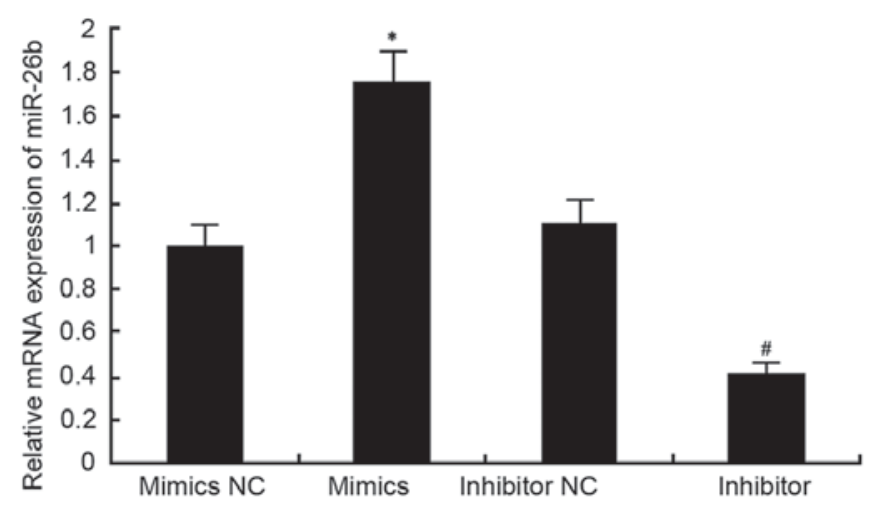

Figure 1. miR-26b expression in U87 cells. Data are expressed as the mean \pm standard deviation. ${ }^{*} \mathrm{P}<0.05$ vs. mimics $\mathrm{NC}$ group; ${ }^{~} \mathrm{P}<0.05$ vs. inhibitor NC group. miR, microRNA; NC, negative control.

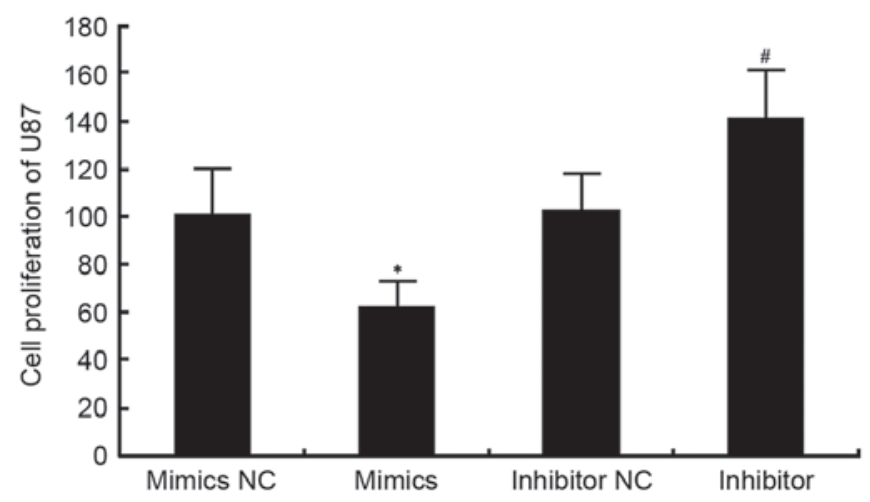

Figure 2. U87 cell proliferation by microRNA-26b transfection. Data are expressed as the mean \pm standard deviation. ${ }^{*} \mathrm{P}<0.05$ vs. mimics $\mathrm{NC}$ group; ${ }^{\#} \mathrm{P}<0.05$ vs. inhibitor NC group. NC, negative control.

contrast, transfection of the miR-26b inhibitor in U87 cells to silence miR-26b expression facilitated U87 cell proliferation $(\mathrm{P}<0.05$ vs. inhibitor group, Fig. 2). These results suggested that the overexpression of miR-26b in U87 cells benefited the abnormal proliferation of glioma cells.

miR-26b regulation on U87 cell invasion. A Transwell chamber was used to detect the effect of miR-26b mimics/inhibitors on the invasion potency of U87 cells. The results showed that the upregulation of miR-26b by transfecting its mimics significantly inhibited cell invasion potency $(\mathrm{P}<0.05$ vs. mimics NC group). In contrast, the transfection of miR-26b inhibitor on U87 cells facilitated U87 cell invasion via silencing miR-26b expression but without statistical 

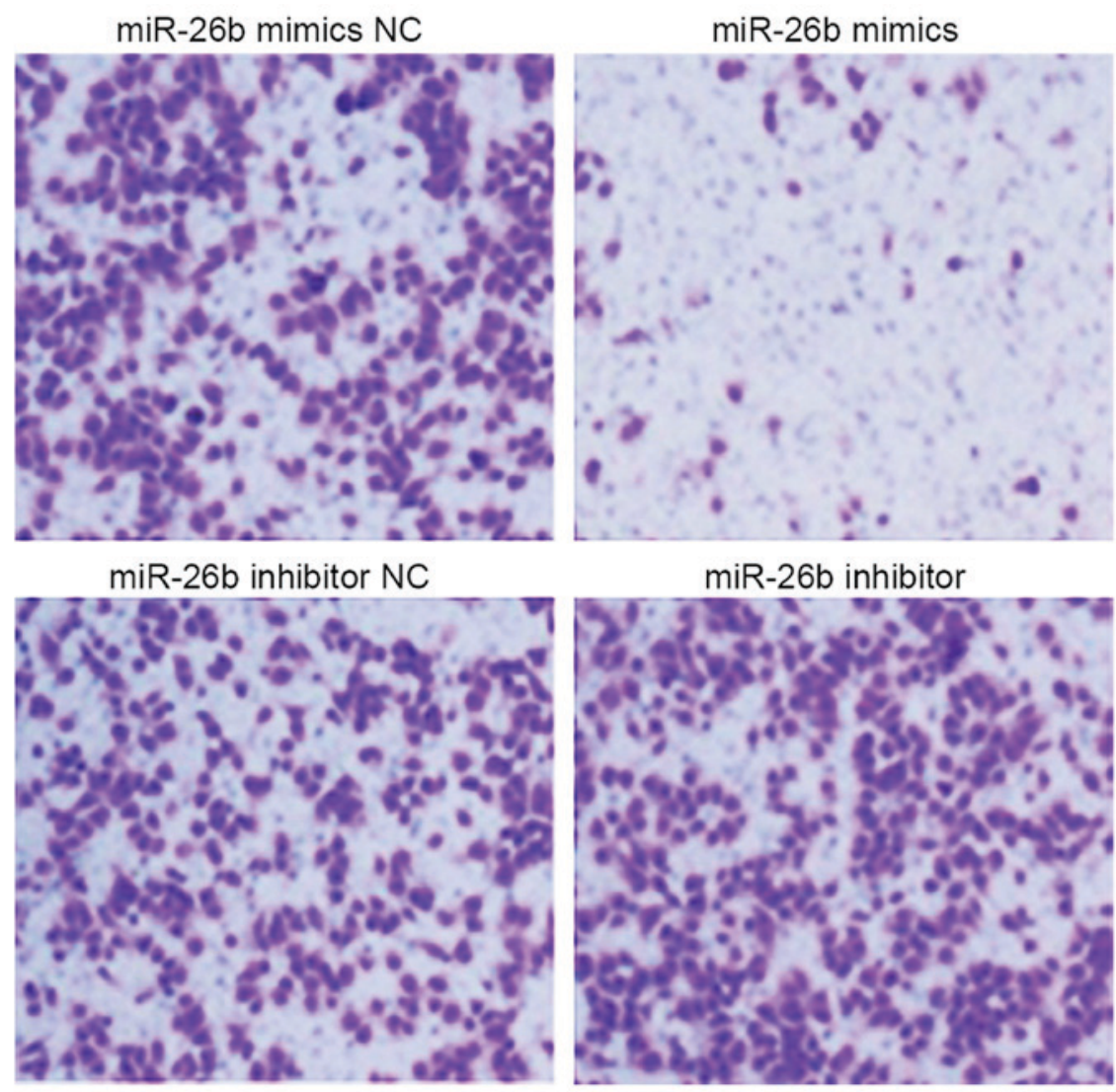

Figure 3. U87 cell invasion by miR-26b regulation. Magnification, x200. miR, microRNA; NC, negative control.

significance ( $\mathrm{P}>0.05$ vs. inhibitor NC group; Figs. 3 and 4). These results collectively suggested that the dynamic change of miR-26b in U87 cells affected the cell invasion potency of tumor cells, as miR-26b overexpression benefited the inhibition of glioma cell invasion.

Caspase-3 activity of U87 cells. A caspase-3 activity assay kit was used to analyze the effect of miR-26b on caspase-3 activity in U87 cells. The results showed that the upregulation of miR-26b by miR-26b mimics significantly potentiated caspase- 3 activity ( $\mathrm{P}<0.05$ vs. mimics $\mathrm{NC}$ group). The transfection of miR-26b inhibitor and resulting downregulation of miR-26b inhibited caspase-3 activity $(\mathrm{P}<0.05$; Fig. 5). These data indicated that the overexpression of U87 cells could facilitate neuroglioma cell apoptosis via enhancing caspase-3 activity.

Bcl-2 mRNA expression levels in U87 cells under miR-26b regulation. RT-qPCR was used to detect the effect of miR-26b on Bcl-2 mRNA expression levels in U87 cells. The results demonstrated that after transfecting miR-26b mimics, upregulation of miR-26b significantly downregulated Bcl-2 mRNA expression levels ( $\mathrm{P}<0.05$ vs. mimics $\mathrm{NC}$ group). In contrast, the transfection of miR-26b inhibitor to downregulate miR-26b expression elevated Bcl-2 mRNA expression $(\mathrm{P}<0.05$ vs. inhibitor NC group, Fig. 6).

Regulation of miR-26b on $\mathrm{Bcl}-2$ protein by $U 87$ cells. Western blotting was used to detect the effect of miR-26b on Bcl-2 protein expression in U87 cells. The results demonstrated that

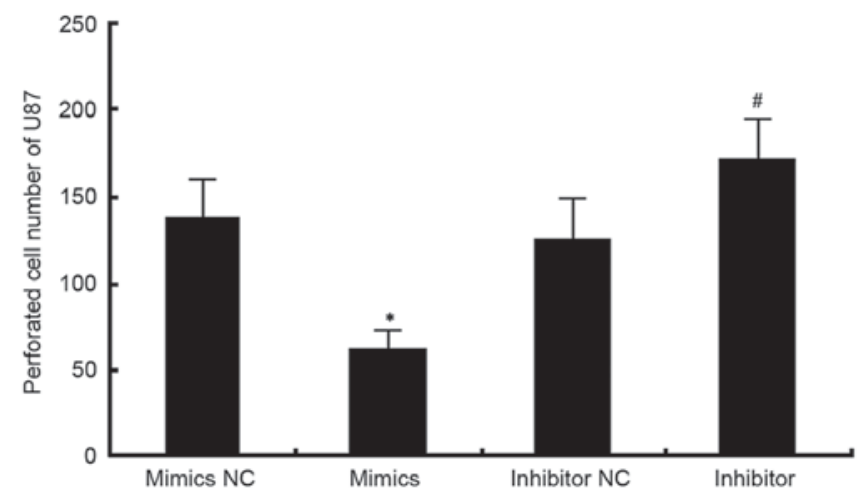

Figure 4. Analysis of the effect of microRNA-26b on U87 cell invasion. Data are expressed as the mean \pm standard deviation. ${ }^{*} \mathrm{P}<0.05$ vs. mimics $\mathrm{NC}$ group; ${ }^{\text {}} \mathrm{P}<0.05$ vs. inhibitor $\mathrm{NC}$ group. $\mathrm{NC}$, negative control.

the transfection of miR-26b mimics significantly downregulated $\mathrm{Bcl}-2$ protein expression ( $\mathrm{P}<0.05$ vs. mimics $\mathrm{NC}$ group). In contrast, U87 cells transfected with an miR-26b inhibitor increased $\mathrm{Bcl}-2$ protein expression $(\mathrm{P}<0.05$ vs. inhibitor $\mathrm{NC}$ group, Figs. 7 and 8).

\section{Discussion}

Among all malignant tumors in the nervous system, glioma has a high incidence and unfavorable prognosis, causing difficulty in clinical treatment, and heavy economic and mental burdens for patients and families. Although various treatment plans have been developed for glioma, its 5-year survival rate 


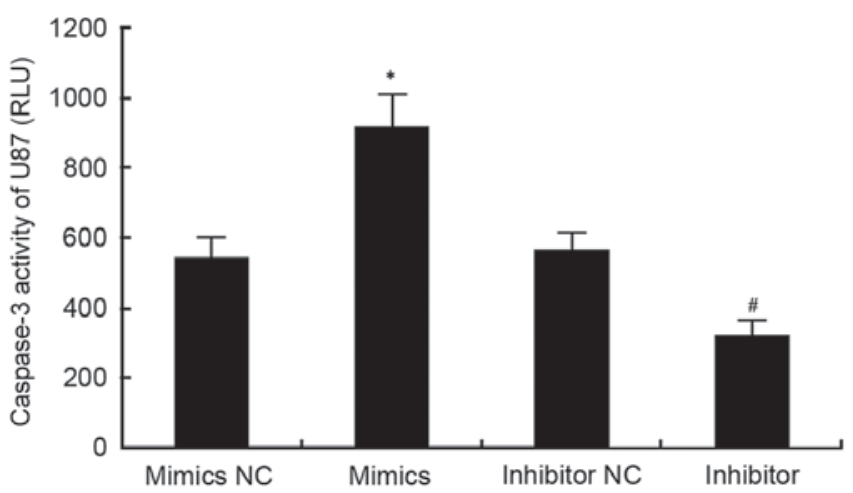

Figure 5. Effect of microRNA-26b on caspase-3 activity of U87 cells. Data are expressed as the mean \pm standard deviation. ${ }^{*} \mathrm{P}<0.05$ vs. mimics $\mathrm{NC}$ group; ${ }^{\text {P }}<0.05$ vs. inhibitor $\mathrm{NC}$ group. $\mathrm{NC}$, negative control; RLU, relative light units.

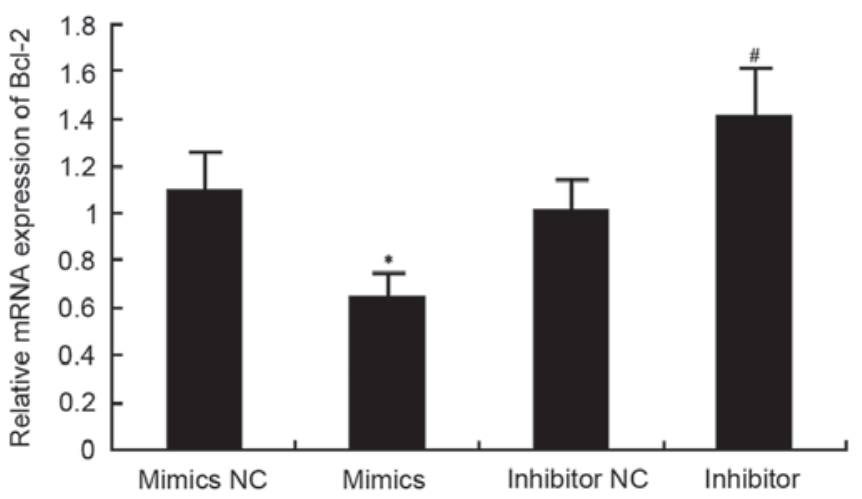

Figure 6. Regulation of Bcl-2 mRNA by microRNA-26b in U87 cells. Data are expressed as the mean \pm standard deviation. ${ }^{*} \mathrm{P}<0.05$ vs. mimics NC group; ${ }^{*} \mathrm{P}<0.05$ vs. inhibitor $\mathrm{NC}$ group. $\mathrm{Bcl}-2$, B-cell lymphoma 2 ; $\mathrm{NC}$, negative control.

remains low, and combined with the high recurrence after surgical resection, glioma has now become a refractory tumor of primary concern in modern medicine $(18,19)$. Such tumor recurrence and refractory properties are closely associated with the invasion/migration features. As the migration and invasion of glioma involve tumor cell adhesion, cell apoptosis and other factors, it is a complicated pathological process (20).

Since its discovery in the 1990s, miRs have research hotspots due to their functions in post-transcriptional regulation and multiple biological processes. miRs can regulate various target genes including cell growth factors, transcription factors, cell death genes and other signaling molecules, further facilitating or inhibiting cell proliferation, differentiation, apoptosis and death (21). miRs can regulate metabolism and development/growth at the post-transcriptional level (22). miR-26b is widely distributed in various tissues/organs, and is closely associated with normal functions and development of the eye or liver (23). The present study confirmed the inhibition of glioma cell proliferation or invasion by overexpressing miR-26b in glioma cells via transfecting miR-26b mimic oligonucleotides. The transfection of miR-26 inhibitor, however, could significantly suppress its expression in glioma cells, whose proliferation and invasion were all potentiated. These results were consistent with a previous report demonstrating

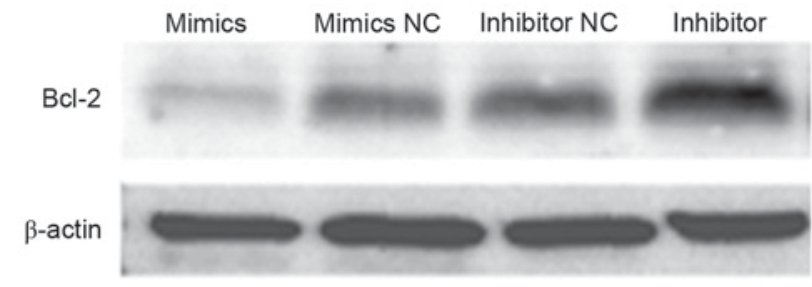

Figure 7. Bcl-2 protein expression in U87 cells by miR-26b expression. Representative western blot images are presented. Bcl-2, B-cell lymphoma 2; NC, negative control.

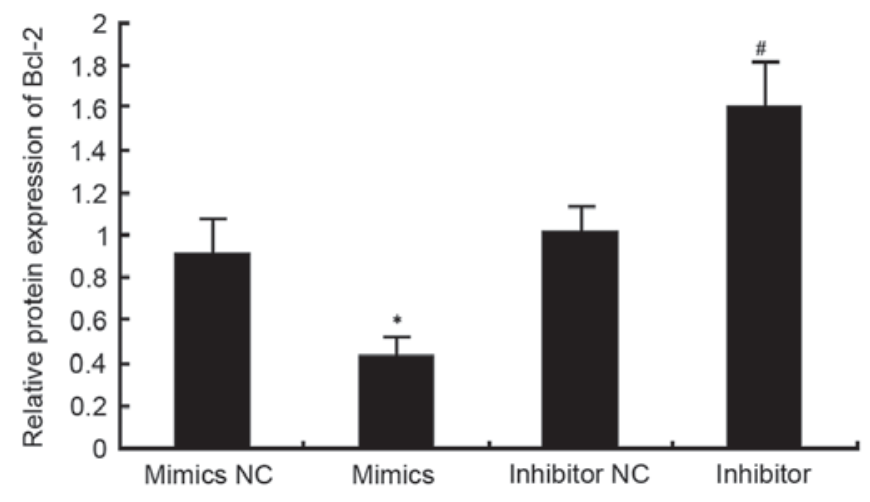

Figure 8. Quantitative analysis of Bcl-2 protein expression in U87 cells. Data are expressed as the mean \pm standard deviation. ${ }^{*} \mathrm{P}<0.05$ vs. mimics $\mathrm{NC}$ group; ${ }^{\text {P }}<0.05$ vs. inhibitor NC group. Bcl-2, B-cell lymphoma 2; NC, negative control.

the participation of miR-26b in glioma cell proliferation and invasion across different U87 cell lines (24). Therefore, further study regarding the mechanism of miR-26b in glioma cells is required. Cell apoptosis is the regulation of body homeostasis and has pivotal roles in tumor pathogenesis. The depressed apoptosis level and over-proliferation of tumors cells all elevate the probability of tumor progression and invasion or metastasis (25). The over-expression of the anti-apoptotic gene Bcl-2 leads to abnormal proliferation of tumor cells and diminished apoptosis of necrotic cells, all of which are important factors causing tumor formation and progression, making the progression of tumor uncontrollable (26). The initiation of the cell apoptotic program can inhibit tumor growth and facilitate activation of the apoptosis family of proteins, in which caspase- 3 is one of the most important members. The elevated activity of caspase-3 could induce tumor cell apoptosis (27). The present study confirmed that the transfection of miR-26b mimics and consequent overexpression of miR-26b remarkably downregulates the mRNA and protein expression levels of Bcl-2, whilst upregulating caspase-3 activity. In contrast, the transfection of an inhibitor significantly suppressed miR-26b expression, upregulated $\mathrm{Bcl}-2 \mathrm{mRNA} /$ protein expression and decreased caspase- 3 activity. These results demonstrated the role of miR-26b on glioma cell proliferation/invasion and further occurrence and progression of tumors via affecting Bcl-2 expression and caspase-3 activity for exerting effects on cell apoptosis.

In conclusion, miR-26b may facilitate glioma cell apoptosis and inhibit its proliferation or invasion, via downregulating Bcl-2 expression and enhancing caspase- 3 activity. The present 
study provided theoretical evidence and a basis for selecting novel molecular targets of glioma in clinics.

\section{References}

1. Jiao JT, Jiang C, Huang J, Dai MC, Wang C, Cheng C and Shao JF: Metabolic syndrome factors and risk of postoperative depression in high-grade glioma patients in a 1.5-year prospective study. Med Oncol 31: 234, 2014.

2. Waghmare I, Roebke A, Minata M, Kango-Singh M and Nakano I: Intercellular cooperation and competition in brain cancers: Lessons from Drosophila and human studies. Stem Cells Transl Med 3: 1262-1268, 2014.

3. Anderson G and Maes M: Local melatonin regulates inflammation resolution: A common factor in neurodegenerative, psychiatric and systemic inflammatory disorders. CNS Neurol Disord Drug Targets 13: 817-827, 2014

4. Young JS, Morshed RA, Kim JW, Balyasnikova IV, Ahmed AU and Lesniak MS: Advances in stem cells, induced pluripotent stem cells, and engineered cells: Delivery vehicles for anti-glioma therapy. Expert Opin Drug Delivery 11: 1733-1746, 2014.

5. Chung DS, Shin HJ and Hong YK: A new hope in immunotherapy for malignant gliomas: Adoptive T cell transfer therapy. J Immunol Res 2014: 326545, 2014.

6. Lim YC, Roberts TL, Day BW, Stringer BW, Kozlov S, Fazry S, Bruce ZC, Ensbey KS, Walker DG, Boyd AW and Lavin MF: Increased sensitivity to ionizing radiation by targeting the homologous recombination pathway in glioma initiating cells Mol Oncol 8: 1603-1615, 2014

7. Belcaid Z, Phallen JA, Zeng J, See AP, Mathios D, Gottschalk C, Nicholas S, Kellett M, Ruzevick J, Jackson E, et al: Focal radiation therapy combined with 4-1BB activation and CTLA-4 blockade yields long-term survival and a protective antigen-specific memory response in a murine Glioma model. PLoS One 9: e101764, 2014

8. Ramachandran R, Malarvizhi GL, Chandran P, Gupta N, Menon D Panikar D, Nair S and Koyakutty M: A polymer-protein core-shell nanomedicine for inhibiting cancer migration followed by photo-triggered killing. J Biomed Nanotechnol 10: 1401-1415, 2014

9. Avdieiev S, Gera L, Havrylyuk D, Hodges RS, Lesyk R, Ribrag V, Vassetzky Y and Kavsan V: Bradykinin antagonists and thiazolidinone derivatives as new potential anti-cancer compounds. Bioog Med chem 22: 3815-3823, 2014

10. Wang G, Sai K, Gong F, Yang Q, Chen F and Lin J: Mutation of isocitrate dehydrogenase 1 induces glioma cell proliferation via nuclear factor- $\mathrm{\kappa B}$ activation in a hypoxia-inducible factor 1-o dependent manner. Mol Med Rep 9: 1799-1805, 2014.

11. Gallach S, Calabuig-Farinas S, Jantus-Lewintre E and Camps C: MicroRNAs: Promising new antiangiogenic targets in cancer. Biomed Res Int 2014: 878450, 2014.

12. Orang AV and Barzegari A: MicroRNAs in colorectal cancer: From diagnosis to targeted therapy. Asian Pac J Cancer Prev 15: 6989-6999, 2014.
13. LiE, Ji P, Ouyang N,Zhang Y, Wang XY, Rubin DC, Davidson NO, Bergamaschi R, Shroyer KR, Burke S, et al: Differential expression of miRNAs in colon cancer between African and Caucasian Americans: Implications for cancer racial health disparities. Int J Oncol 45: 587-594, 2014.

14. Mao C, Liu H, Chen P, Ye J, Teng L, Jia Z and Cao J: Cell-specific expression of artificial microRNAs targeting essential genes exhibit potent antitumor effect on hepatocellular carcinoma cells. Oncotarget 6: 5707-5719, 2015

15. Li J, Kong X, Zhang J, Luo Q, Li X and Fang L: MiRNA-26b inhibits proliferation by targeting PTGS2 in breast cancer. Cancer Cell Int 13: 7, 2013.

16. Gragnani L, Fognani E, Piluso A and Zignego AL: Hepatitis C-associated B-cell non-Hodgkin lymphomas: The emerging role of miRNA-26b. J hepatol 59: 1362-1363, 2013.

17. Livak KJ and Schmittgen TD: Analysis of relative gene expression data using real-time quantitative PCR and the 2(-Delta Delta C(T)) Method. Methods 25: 402-408, 2001.

18. Rathod SS, Rani SB, Khan M, Muzumdar D and Shiras A: Tumor suppressive miRNA-34a suppresses cell proliferation and tumor growth of glioma stem cells by targeting Akt and Wnt signaling pathways. FEBS Open Bio 4: 485-495, 2014.

19. Wang L, Shi ZM, Jiang CF, Liu X, Chen QD, Qian X, Li DM, Ge X, Wang XF, Liu LZ, et al: MiR-143 acts as a tumor suppressor by targeting N-RAS and enhances temozolomide-induced apoptosis in glioma. Oncotarget 5: 5416-5427, 2014

20. Brower JV, Clark PA, Lyon W and Kuo JS: MicroRNAs in cancer: Glioblastoma and glioblastoma cancer stem cells. Neurochem Int 77: 68-77, 2014.

21. Yao W, Guo G, Zhang Q, Fan L, Wu N and Bo Y: The application of multiple miRNA response elements enables oncolytic adenoviruses to possess specificity to glioma cells. Virology 458-459: 69-82, 2014.

22. Shi Z, Chen Q, Li C, Wang L, Qian X, Jiang C, Liu X, Wang X, $\mathrm{Li} \mathrm{H}$, Kang C, et al: MiR-124 governs glioma growth and angiogenesis and enhances chemosensitivity by targeting R-Ras and N-Ras. Neuro-oncol 16: 1341-1353, 2014.

23. Liu J, Tu F, Yao W, Li X, Xie Z, Liu H, Li Q and Pan Z: Conserved miR-26b enhances ovarian granulosa cell apoptosis through HAS2-HA-CD44-Caspase-3 pathway by targeting HAS2. Sci Rep 6: 21197, 2016.

24. Xia G, Bao L, Gao W, Liu S, Ji K and Li J: Differentially expressed miRNA in inflammatory mucosa of chronic rhinosinusitis. J Nanosci Nanotechnol 15: 2132-2139, 2015.

25. Wong RS: Apoptosis in cancer: From pathogenesis to treatment. J Exp Clin Cancer Res 30: 87, 2011.

26. Zerp SF, Stoter TR, Hoebers FJ, van den Brekel MW, Dubbelman R, Kuipers GK, Lafleur MV, Slotman BJ and Verheij M: Targeting anti-apoptotic Bcl-2 by AT-101 to increase radiation efficacy: Data from in vitro and clinical pharmacokinetic studies in head and neck cancer. Radiat Oncol 10: 158, 2015.

27. Yang J, Wei D, Wang W, Shen B, Xu S and Cao Y: TRAF4 enhances oral squamous cell carcinoma cell growth, invasion and migration by Wnt- $\beta$-catenin signaling pathway. Int J Clin Exp Pathol 8: 11837-11846, 2015. 